\title{
Conjunctival hyperaemia with the use of latanoprost versus other prostaglandin analogues in patients with ocular hypertension or glaucoma: a meta-analysis of randomised clinical trials
}

\author{
F Honrubia, ${ }^{1}$ J García-Sánchez, ${ }^{2}$ V Polo, ${ }^{1}$ J M Martínez de la Casa, ${ }^{2}$ J Soto ${ }^{3}$
}

${ }^{1}$ Ophthalmology Service, Hospital Miguel Servet,

Zaragoza, Spain;

2 Ophthalmology Service

Hospital Clínico, Madrid, Spain

${ }^{3}$ Medical Unit, Pfizer Spain,

Madrid, Spain

Correspondence to:

Dr J Soto, Medical Unit, Pfizer Spain, Avda de Europa 20-B,

Parque Empresarial de la Moraleja, 28108 Alcobendas,

Madrid, Spain; javier.soto.

alvarez@pfizer.com

Accepted 15 October 2008

Published Online First

19 November 2008

\begin{abstract}
Aim: To conduct a meta-analysis of randomised clinical trials (RCTs) in order to evaluate the development of conjunctival hyperaemia after the use of latanoprost versus travoprost and bimatoprost, in patients with ocular hypertension or glaucoma
\end{abstract}

Methods: In order to identify the potentially relevant RCTs, a systematic literature retrieval was conducted in Medline, Embase and Cochrane Controlled Trials Register (1995-April 2007) databases The outcome measure was the appearance of conjunctival hyperaemia during the study. Statistical analyses included the calculation of odds ratio $(\mathrm{OR})$ and its respective confidence interval, along with intertrial statistical heterogeneity. Publication bias was evaluated through a funnel plot, and a sensitivity analysis was also performed.

Results: In total, 13 RCTs involving 2222 patients with ocular hypertension or glaucoma were included, five comparing latanoprost versus travoprost, seven comparing latanoprost versus bimatoprost and one comparing latanoprost versus travoprost and bimatoprost. The combined results showed that latanoprost produced lower occurrence of conjunctival hyperaemia than both travoprost $(\mathrm{OR}=0.51 ; 95 \% \mathrm{Cl} 0.39$ to $0.67, \mathrm{p}<0.0001$ ) and bimatoprost $(\mathrm{OR}=0.32 ; 95 \% \mathrm{Cl} 0.24$ to 0.42 , $p<0.0001)$. No significant heterogeneity was found between the included RCTs. There was no evidence of publication bias. In the sensitivity analysis performed, none of the clinical trials included in this meta-analysis has an important impact in the global estimation of $\mathrm{OR}$. Conclusions: According to available data, the use of latanoprost is associated with a lower incidence of conjunctival hyperaemia when compared with travoprost and bimatoprost in the treatment of patients with ocular hypertension or glaucoma

The estimated prevalence of glaucoma is $2 \%$ in the general population, $3 \%$ in people over $50,5.7 \%$ in subjects 73 and 74 years old and $23.2 \%$ in those aged 75 years and older. This number is expected to increase in the future, given the progressive ageing of the population. ${ }^{1-3}$

For patients with ocular hypertension or openangle glaucoma, drug therapy focuses on reducing intraocular pressure (IOP) levels in order to delay or prevent the progression of ocular hypertension to glaucoma, and to slow disease progression in glaucoma patients. ${ }^{45}$ In both cases, patients require lifelong treatment and follow-up care to preserve vision, so it is essential long-term patient compliance and medication persistency, because those who do not continue therapy risk developing elevated IOP levels and, over time, progressing to blindness. ${ }^{6}$

Compliance and persistency depends on many factors, including patient satisfaction with medication, medication costs, ease of medication administration and patient understanding of the importance of taking their medication over the long term, although one of the most important factors is local and systemic side effects.

Currently, first-line treatment usually consists of monotherapy with a topical hypotensive drug. Although ophthalmologists traditionally have prescribed beta-blockers as first-line ocular hypotensive therapy, due to the possibility of producing systemic side effects, other therapeutic options are currently preferred, with prostaglandin analogues being one of the most widely used.

Topical prostaglandins such as latanoprost, bimatoprost and travoprost are similar in that they require once-daily instillation, produce few systemic side effects and reduce IOP levels similarly. ${ }^{9-11}$ However, some prostaglandin-treated patients experience conjunctival hyperaemia, ${ }^{12}$ and this condition is of concern because this side effect may have a negative affect on whether the patient takes the drug as directed (compliance) and/or continues to use the drug over time (persistency).

Although a lower rate of conjunctival hyperaemia has been reported with latanoprost in contrast to bimatoprost and travoprost, ${ }^{13}$ no systematic review and meta-analysis has examined this issue. Therefore, the aim of this work was to conduct a meta-analysis of RCTs comparing latanoprost against bimatoprost and travoprost, either together or in separated studies, in patients with ocular hypertension and/or glaucoma.

\section{METHODS}

\section{Search strategy}

Reports of RCTs comparing latanoprost, bimatoprost and travoprost were identified through a systematic search. A computerised literature search was conducted in Medline, Embase and Cochrane Controlled Trials Register databases from 1995 to April 2007 for relevant articles in English.

We used the Medical Subject Heading and the following key words: glaucoma, ocular hypertension, randomisation, trial, latanoprost, bimatoprost, travoprost and conjunctival/ocular online under the BMJ Journals unlocked scheme, see http:// bjo.bmj.com/info/unlocked.dtl 
Figure 1 Selection algorithm for the randomised controlled trials (RCTs) included in this meta-analysis.

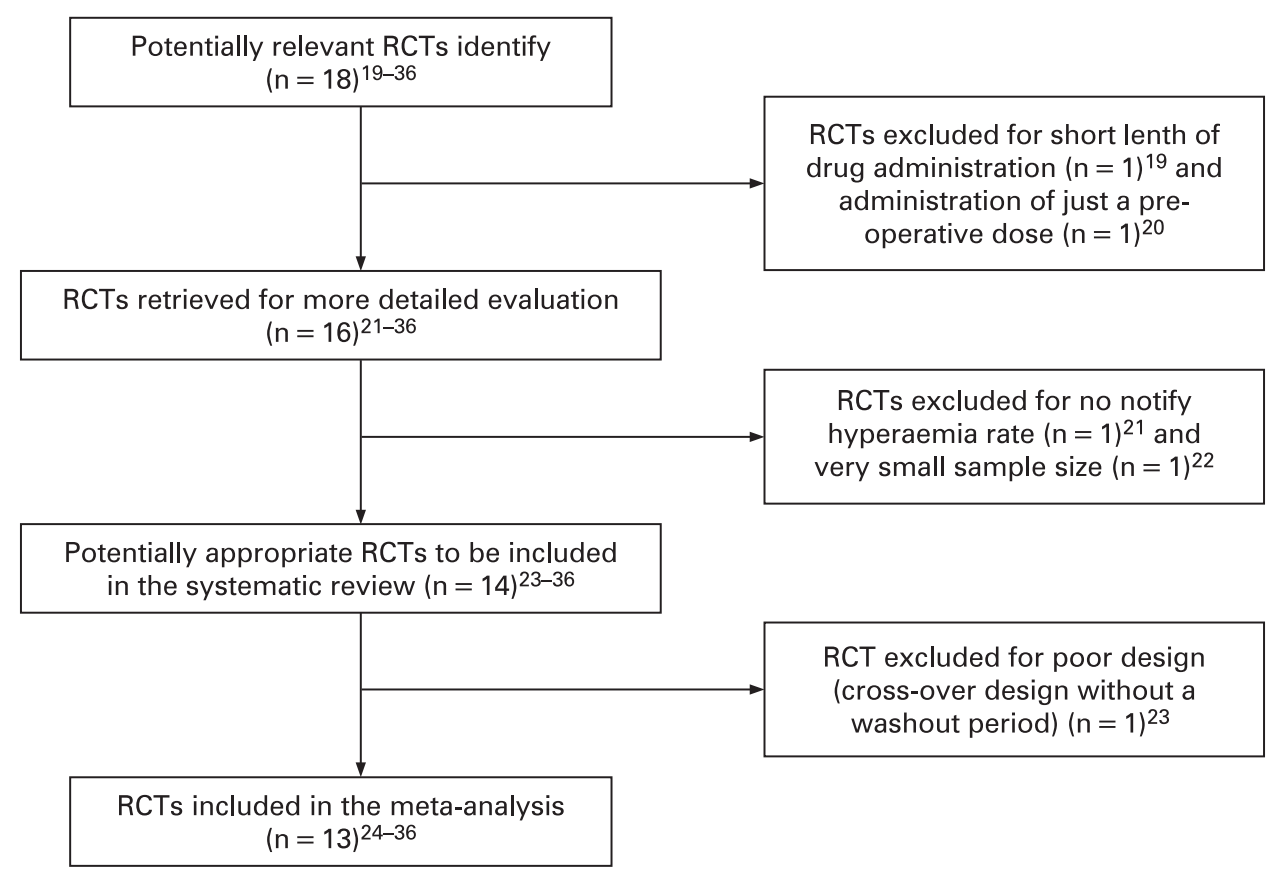

hyperaemia. References from the reviewed articles were also searched for relevant titles.

\section{Study selection}

Two reviewers independently conducted the literature search and extraction of relevant articles. The title and abstract of potentially relevant studies and review articles were screened for appropriateness before retrieval of the full articles.

The following selection criteria were used to identify published studies for inclusion in this meta-analysis: (a) study design-RCTs in adults (age $>18$ years); (b) populationpatients with ocular hypertension and/or glaucoma; (c) intervention-latanoprost versus other prostaglandins analogues (bimatoprost or travoprost) as monotherapy; (d) outcome variable-conjunctival hyperaemia. These articles were written in English. Abstracts from conferences without raw data available for retrieval and duplicate publications were excluded.

\section{Data extraction}

Two reviewers performed separately the data extraction and methodological quality assessment of trials that were included. The reviewers were blinded for the names of the authors and their institution, the names of the journals, sources of funding and acknowledgments. Any disagreements between the reviewers were resolved by discussion to reach consensus. A third reviewer was involved when required.

A customised form was created to record the information of selected articles: year of publication, information of study design (double-blind, parallel or crossover), length of study, number of subjects, age, sex, type of glaucoma and proportion of conjunctival hyperaemia.

The primary outcomes measure was the incidence of conjunctival hyperaemia over treatment visits. The reason for exclusion was recorded on a standard form. Excluded publications were reassessed to ensure that all eligible publications were included.
Model Study name

Netland 2001
Parrish 2003
Parmaksiz 2006
Chen 2006
Garcia-Feijoo 2006
Konstas 2007

Fixed Random

\begin{tabular}{|c|c|c|c|c|c|}
\hline \multirow[b]{2}{*}{$\begin{array}{l}\text { Odds } \\
\text { ratio }\end{array}$} & \multicolumn{5}{|c|}{ Hyperaemia/total } \\
\hline & $\begin{array}{l}\text { Lower } \\
\text { limit }\end{array}$ & $\begin{array}{l}\text { Upper } \\
\text { limit }\end{array}$ & Latanoprost & Travoprost & Total \\
\hline 0.494 & 0.341 & 0.716 & $54 / 193$ & $177 / 402$ & $231 / 595$ \\
\hline 0.644 & 0.400 & 1.038 & $64 / 136$ & $80 / 138$ & $144 / 274$ \\
\hline 0.105 & 0.011 & 0.979 & $1 / 16$ & $7 / 18$ & $8 / 34$ \\
\hline 0.582 & 0.128 & 2.638 & $3 / 36$ & $5 / 37$ & $8 / 73$ \\
\hline 0.517 & 0.044 & 6.019 & $1 / 30$ & $2 / 32$ & $3 / 62$ \\
\hline 0.294 & 0.100 & 0.865 & $6 / 40$ & $15 / 40$ & $21 / 80$ \\
\hline 0.512 & 0.390 & 0.674 & $129 / 451$ & $286 / 667$ & $415 / 1118$ \\
\hline 0.512 & 0.390 & 0.674 & $129 / 451$ & $286 / 667$ & $415 / 1118$ \\
\hline
\end{tabular}

0.01

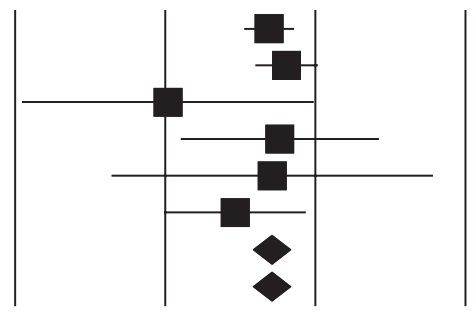

0.1
Odds ratio and $95 \% \mathrm{Cl}$

Favours latanoprost

Favours travoprost

Test for overall effect : $Z=4.78(p<0.00001)$

Figure 2 Global and partial statistical data of clinical trials comparing latanoprost and travoprost. 


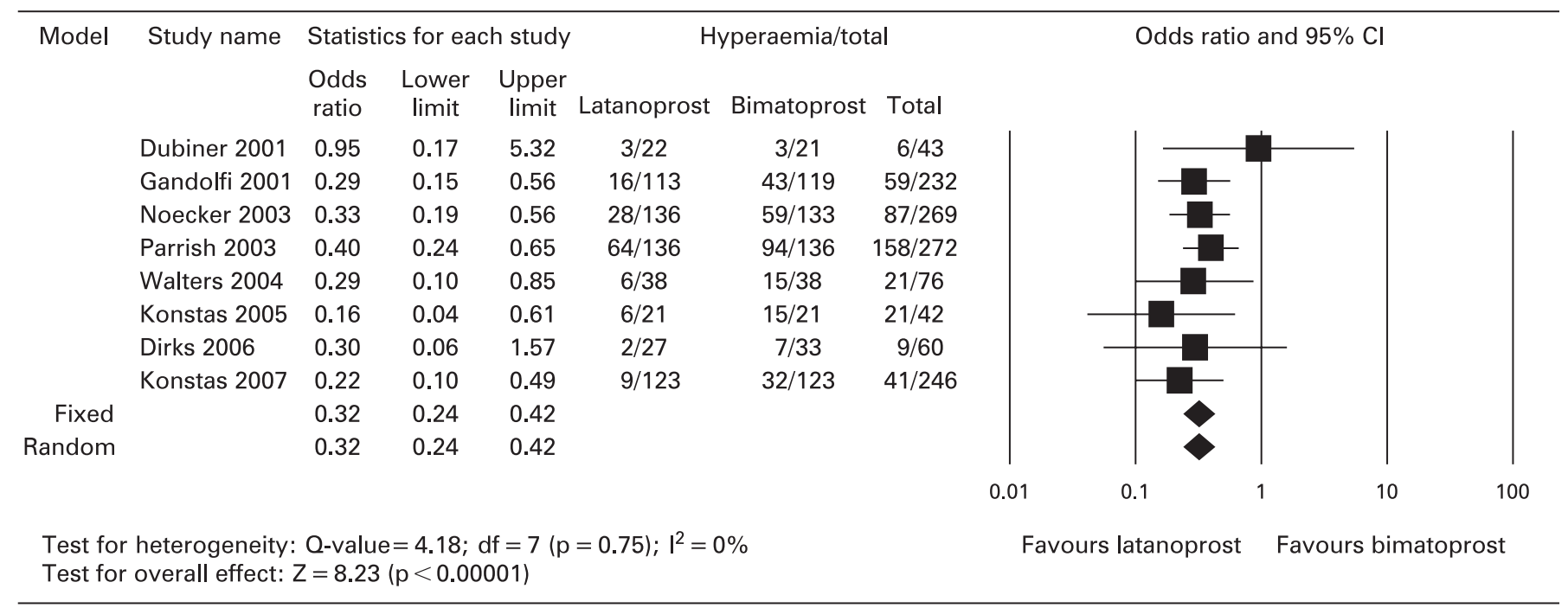

Figure 3 Global and partial statistical data of clinical trials comparing latanoprost and bimatoprost.

\section{Assessment of study quality}

Two reviewers independently rated study quality using the Jadad instrument for the assessment of the quality of trials reports. ${ }^{14}$ This instrument is a point scale ranging from 0 to 8 , with points derived from the description of randomisation, blinding, inclusion and exclusion criteria, withdrawals and method of assessing adverse events.

\section{Statistical methods and assessment of heterogeneity}

The statistical analysis was carried out by Comprehensive Meta-Analysis software version 2.2 (Biostat, Englewood Cliffs, New Jersey) (http://www.meta-analysis.com).

For dichotomous outcomes, we calculated a pooled odds ratio (OR) and 95\% CIs. The OR was defined as the odds of an outcome in those who received latanoprost therapy compared with the odds in those who received bimatoprost or travoprost. The ORs of different RCTs were combined by using the fixed effects model of Mantel and Haenszel ${ }^{15}$ and the random effects model of Der Simonian and Laird. ${ }^{16}$

Intertrial statistical heterogeneity was explored using the Cochran $\mathrm{Q}$ test with calculated $\mathrm{I}^{2}$,indicating the percentage of the total variability in effect estimates among trials that is due to heterogeneity rather than to chance. ${ }^{17} \mathrm{I}^{2}$ values of $50 \%$ or

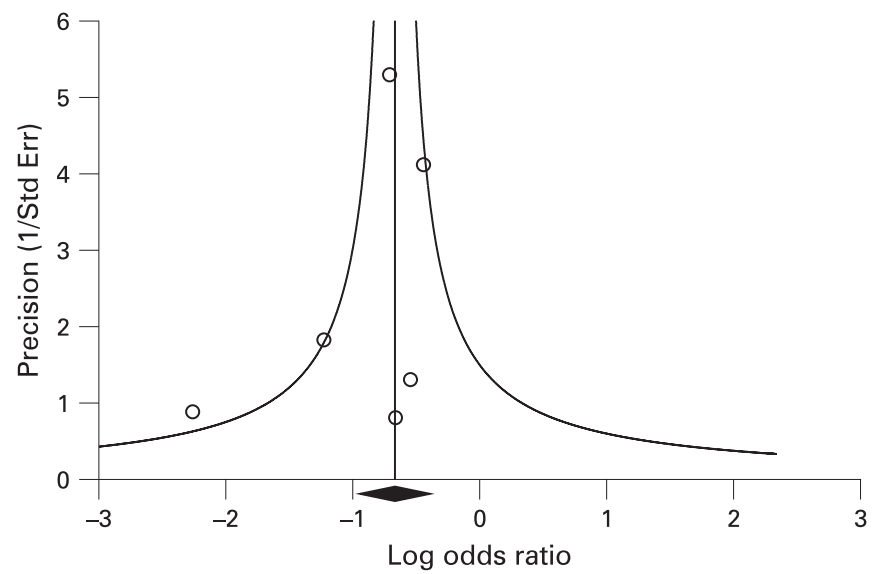

Figure 4 Funnel plot of clinical trials included in the meta-analysis comparing latanoprost vs travoprost. more indicate a substantial level of heterogeneity. Publication bias was assessed by visually inspecting a funnel plot.

All $p$ values were two-sided with statistical significance set at an $\alpha$ level of 0.05 . We followed the Quality of Reporting Metaanalysis guidelines for reporting and discussing these metaanalytical results. ${ }^{18}$

To exclude the possibility that any one study was exerting excessive influence on the results, we conducted a sensitivity analysis by systematically excluding each study at a time and then rerunning the analysis to assess the change in ORs.

\section{RESULTS}

\section{Literature search}

There were 31 articles relevant to the search term. A total of 18 potential RCTs of latanoprost versus other prostaglandin analogues were identified through the literature search, ${ }^{19-36}$ five comparing latanoprost vs travoprost, seven comparing latanoprost vs bimatoprost and one comparing latanoprost vs bimatoprost and travoprost.

Finally, 13 articles involving 2222 patients with ocular hypertension or glaucoma were included in this meta-analysis. ${ }^{24-36}$ The algorithm flow chart for the selection of RCTs to be included in our analysis is shown in fig 1.

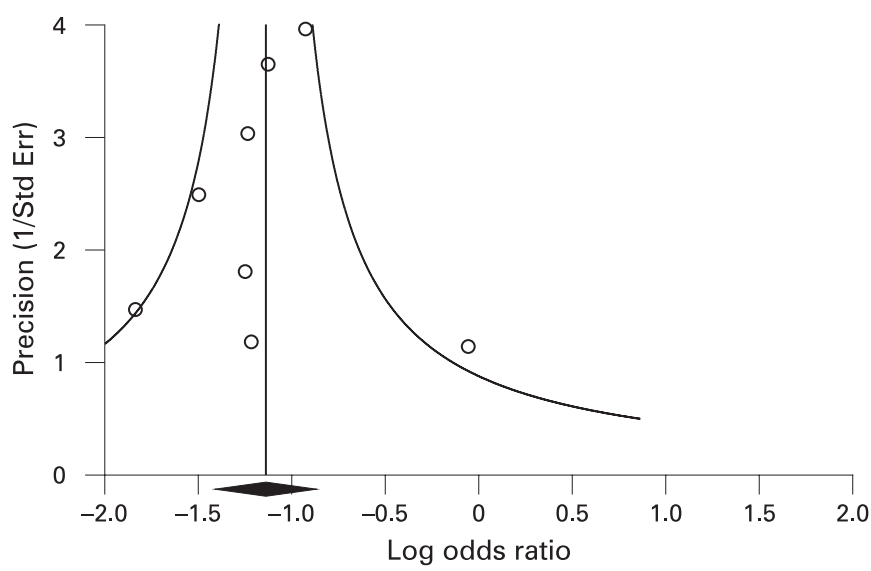

Figure 5 Funnel plot of clinical trials included in the meta-analysis comparing latanoprots vs bimatoprost. 


\section{Characteristics of trials}

Table 1 shows the characteristics of the RTCs that were included in this meta-analysis. Overall, 2222 patients were evaluated for an average period of follow-up of 4.1 months ( $\min =2$ weeks; $\max =9$ months). Nine hundred and thirtyone patients were treated with latanoprost, 624 with bimatoprost and 667 with travoprost.

Patients' ages ranged from 58 to 73 years with a mean of 65; $41.4 \%$ were men, 1364 patients (61.4\%) suffered from openangle glaucoma, 678 (30. 5\%) from ocular hypertension and 180 (8.1\%) from another type of glaucoma (chronic angle-closure glaucoma, exfoliative glaucoma and pigmentary glaucoma).

The proportion of patients treated with latanoprost who developed conjunctival hyperaemia was $16.5 \% \quad(\min =3.3 \%$; $\max =47.1 \%)$, in the bimatoprost group $40.2 \%(\min =14.3 \%$; $\max =68.6 \%)$ and in the travoprost group $33 \%(\min =6.2 \%$; $\max =58 \%$ ).

\section{Hyperaemia outcome}

The combined results of different clinical trials suggested that the use of latanoprost $0.005 \%$ caused a lower percentage of appearance of conjunctival hyperaemia compared with travoprost $0.004 \%(\mathrm{OR}=0.51 ; 95 \% \mathrm{CI} 0.39$ to $0.67, \mathrm{p}<0.00001)$. No significant heterogeneity was found between included clinical trials $(\mathrm{Q}=3.98$; $\mathrm{p}=0.56$ ) (fig 2).

Moreover, the results of this meta-analysis also showed that the utilisation of latanoprost $0.005 \%$ is associated with a lower development of conjunctival hyperaemia when compared with bimatoprost $0.003 \% \quad(\mathrm{OR}=0.32 ; \quad 95 \% \quad \mathrm{CI} \quad 0.24$ to 0.42 , $\mathrm{p}<0.00001)$. Heterogeneity between included clinical trials did not show any significance $(Q=4.18 ; p=0.75)$ (fig 3$)$.

\section{Sensitivity analysis}

In order to analyse the consistency and robustness of the results, a sensitivity analysis was performed (table 2). First, the results obtained were compared using the fixed and random models. Changing the model from fixed to random effects did not change the results of our meta-analysis.
Second, in order to assess the influence of each individual clinical trial included in the meta-analysis, each study was excluded at a time and the analysis performed again to determine the change in the OR. The punctual estimators for OR vary between 0.46 and 0.54 in the latanoprost-travoprost analysis, and between 0.29 and 0.34 in the latanoprostbimatoprost analysis after excluding one by one each original clinical trial. None of the clinical trials included in this metaanalysis had an important impact in the global estimation of the OR.

\section{Publication bias}

An analysis of publication bias was conducted. For each separate analysis (latanoprost-travoprost and latanoprost-bimatoprost), based on a visual analysis of the funnel plots, no evidence of publication bias was found (figs 4, 5).

\section{DISCUSSION}

The hypotensive prostaglandin analogues are a novel class of intraocular-lowering medications used primarily for the treatment of glaucoma. In recent years, prostaglandins have emerged as the mainstay of treatment for ocular hypertension and/or glaucoma. These include latanoprost, travoprost and bimatoprost, which are ester or amide pro-drug analogues of the prostaglandin F2-alpha.

The efficacy in lowering IOP of the three compounds is very similar, and in a recent meta-analysis it was found that the difference in decreasing IOP between the three products was very small. ${ }^{37}$ However, according to the literature, it has been described that conjunctival hyperaemia occurs more frequently with either bimatoprost and travoprost than with latanoprost, ${ }^{12} 1338$ although neither systematic review nor metaanalysis has been performed to date to assess this issue properly. The reason for the reduction in hyperaemia caused by latanoprost in the eye compared with bimatoprost and travoprost likely lies in the latanoprost molecule and its pharmacological receptor profile. ${ }^{39}$

Table 1 Characteristics of 13 trials meeting criteria for inclusion in the meta-analysis

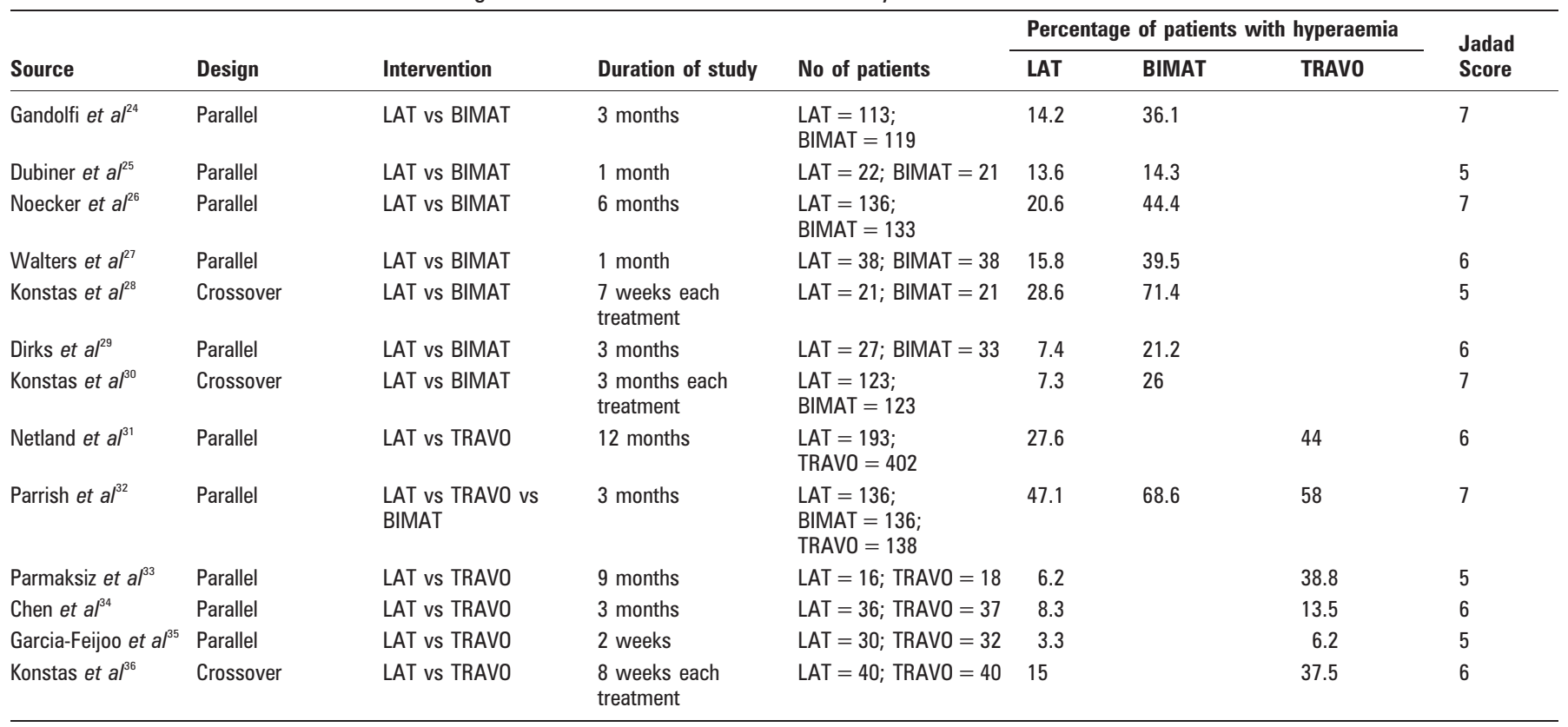


Table 2 Sensitivity analysis of the association of conjunctival hyperaemia and the use of latanoprost, travoprost and bimatoprost

\begin{tabular}{|c|c|c|c|}
\hline \multicolumn{4}{|c|}{ Latanoprost vs bimatoprost } \\
\hline Statistical model & No of studies & No of patients & OR (95\% Cl) \\
\hline Fixed effects & 8 & 1240 & $0.32(0.24$ to 0.42$)$ \\
\hline Random effects & 8 & 1240 & $0.32(0.24$ to 0.42$)$ \\
\hline \multicolumn{4}{|l|}{ Analyses excluding } \\
\hline Dubiner et $a^{25}$ & 7 & 1197 & $0.31(0.24$ to 0.41$)$ \\
\hline Gandolfi et $a l^{24}$ & 7 & 1008 & $0.33(0.24$ to 0.44$)$ \\
\hline Noecker et $a l^{26}$ & 7 & 971 & $0.32(0.23$ to 0.44$)$ \\
\hline Parrish et $\left.a\right|^{32}$ & 7 & 968 & $0.29(0.21$ to 0.40$)$ \\
\hline Walters et $a l^{27}$ & 7 & 1164 & $0.32(0.24$ to 0.43$)$ \\
\hline Konstas et $a l^{28}$ & 7 & 1198 & $0.33(0.25$ to 0.43$)$ \\
\hline Dirks et $a l^{29}$ & 7 & 1180 & $0.32(0.24$ to 0.42$)$ \\
\hline Konstas et $a l^{30}$ & 7 & 994 & $0.34(0.25$ to 0.45$)$ \\
\hline \multicolumn{4}{|c|}{ Latanoprost vs travoprost } \\
\hline Statistical model & No of studies & No of patients & OR (95\% CI) \\
\hline Fixed effects & 6 & 1118 & 0.51 (0.39 to 0.67$)$ \\
\hline Random effects & 6 & 1118 & 0.51 (0.39 to 0.67$)$ \\
\hline \multicolumn{4}{|l|}{ Analyses excluding } \\
\hline Netland et $a l^{31}$ & 5 & 523 & $0.54(0.36$ to 0.80$)$ \\
\hline Parrish et $a l^{32}$ & 5 & 844 & $0.46(0.33$ to 0.64$)$ \\
\hline Parmaksiz et $\left.a\right|^{33}$ & 5 & 1084 & $0.53(0.40$ to 0.69$)$ \\
\hline Chen et $a l^{34}$ & 5 & 1045 & 0.51 (0.39 to 0.67$)$ \\
\hline Garcia-Feijoo et $\left.a\right|^{35}$ & 5 & 1056 & 0.51 (0.39 to 0.68$)$ \\
\hline Konstas et $\left.a\right|^{36}$ & 5 & 1038 & $0.53(0.40$ to 0.71$)$ \\
\hline
\end{tabular}

This meta-analysis was aimed at comparing the development of conjunctival hyperaemia of three prostaglandin analogues on the information reported in the international literature, as conjunctival hyperaemia is a condition of concern, since local side effects may have a negative affect on whether the patient takes the drug as directed (compliance) and/or continues to use the drug over time (persistency). Other local side effects such as the change in iris colour and the development of darker and longer eye lashes may also cause a decrease in treatment compliance and persistency, so it will be necessary to explore this issue in the future by conducting new studies.

The results of this meta-analysis show that the use of latanoprost is associated with a lower incidence of conjunctival hyperaemia. Arcieri et $a l^{40}$ found that there was a significant increase in hyperaemia scores in the latanoprost, bimatoprost and travoprost groups 1 week after baseline. Hyperaemia scores reached their peak 15 days after baseline and started to decrease 1 month after therapy was initiated. Thus, it is important to point out that the conjunctival hyperaemia could decrease during the use of prostaglandin analogues in daily medical practice.

This meta-analysis may have some limitations. First, we cannot fully exclude publication bias, because there were no sufficient studies to detect asymmetry in a funnel plot, and we did not perform a statistical test for the detection of publication bias: these tests have a very low power in meta-analysis of a small number of trials. In addition, we did not attempt to gain access to unpublished results, and only publications written in English were accepted. Second, clinical trials included in this meta-analysis were undertaken in many different countries, so we cannot eliminate location bias. Third, the studies included were heterogeneous in terms of study population, length of each study, number of patients of different studies, basal condition, associated comorbidities and the way of evaluating conjunctival hyperaemia. Access to individual level data could certainly have improved the quality of adjustment as well as the precision of estimates.

\section{CONCLUSION}

The results of this meta-analysis suggest that latanoprost is associated with a lower incidence of conjunctival hyperaemia versus the use of bimatoprost and travoprost in the treatment of ocular hypertension and/or glaucoma. This information may be useful for determining the optimal treatment strategy for individual patients.

More research is needed to determine the incidence of conjunctival hyperaemia after the use of prostaglandin analogues in the mid and long term, as well as in real-world daily medical practice.

Competing interests: JS is an employee of Pfizer Spain. FH, JG-S, VP and JMM have participated in advisory boards for several pharmaceutical companies (Pfizer, Alcon, Allergan and MSD).

\section{REFERENCES}

1. Kroese N, Burton $\mathrm{H}$, Vordy $\mathrm{S}$, et al. Prevalence of primary open-angle glaucoma in general ophthalmic practice in the United Kingdom. $\mathrm{Br} J$ Ophathalmol 2002:86:987-90.

2. Antón A, Andrade MT, Mujice V, et al. Prevalence of open-angle glaucoma in a Spanish population. J Glaucoma 2004;13:371-6.

3. Friedman DS, Jampel HD, Monoz B, et al. The prevalence of open-angle glaucoma among blacks and whites 73 years and older: the Salisbury Eye Evaluation Glaucoma Study. Arch Ophthalmol 2006;124:1625-30.

4. Kass MA, Hever DK, Higginbotham EJ, et al. The ocular hypertension treatment study: a randomized trial determines that topical ocular hypotensive medication delays or prevents the onset of primary open-angle glaucoma. Arch Ophthalmol 2002:120:701-13

5. Laske MC, Heijl A, Hussein M, et al. Factors for glaucoma progression and the effect of treatment: the Early Manifest Glaucoma Trial. Arch Ophthalmol 2003:121:48-56.

6. Schwartz GF. Compliance and persistency in glaucoma follow-up treatment. Curr Opin Ophthalmol 2005;16:114-21.

7. Nordstrom BL, Friedman DS, Mozaffari E, et al. Persistence and adherence with topical glaucoma therapy. Am J Ophthalmol 2005;140:598-606.

8. Kanner E, Tsai JC. Glaucoma medications: use and safety in the elderly population. Drugs Aging 2006;23:321-32. 
9. Hylton C, Robin AL. Update on prostaglandin analogs. Curr Opin Ophtahlmol 2003;14:65-9.

10. van der Valk R, Webers CA, Schorten JS, et al. Intraocular pressure-lowering effects of all commonly used glaucoma drugs: a meta-analysis of randomized clinical trials. Ophthalmology 2005;112:1177-85.

11. Li N, Chen $X$, Zhou Y, et al. Travoprost compared with other prostaglandin analogues or timolol in patients with open-angle glaucoma or ocular hypertension: a metaanalysis of randomized controlled trials. Clin Exp Ophthalmol 2006;34:755-64.

12. Hollo G. The side effects of the prostaglandin analogues. Expert Opin Drug Saf 2007;6:45-52.

13. Feldman RM. Conjunctival hyperemia and the use of topical prostaglandins in glaucoma and ocular hypertension. J Ocul Pharmacol Ther 2003;19:23-35.

14. Jadad AR, Moore RA, Carroll D, et al. Assessing the quality of reports of randomized clinical trials: is blinding necessary? Control Clin Trials 1996;17:1-12.

15. Mantel J, Haenszel W. Statistical aspects of the analysis of data from retrospective studies of disease. J Natl Cancer Inst 1959;22:719-48.

16. Der Simonian R, Laird N. Meta-analysis in clinical trials. Control Clin Trials 1986:7:177-88.

17. Higgins JP, Thompson SG, Deeks JJ, et al. Measuring inconsistency in metaanalyses. BMJ 2003:327:557-60.

18. Moher D, Cook D, Eastwood S, et al. Improving the quality of reports of metaanalyses of randomised controlled trials: the QUORUM statement. Lancet 1999; 354:1896-900.

19. Dubiner HB, Sircy MD, Landry T, et al. Comparison of the diurnal ocular hypotensive efficacy of travoprost and latanoprost over a 44-hour period in patients with elevated intraocular pressure. Clin Ther 2004;26:84-91.

20. Arici MK, Erdogan $\mathrm{H}$, Toker I, et al. The effect of latanoprost, bimatoprost, and travoprost on intraocular pressure after cataract surgery. J Ocul Pharm Ther 2006;22:34-40.

21. Orzalesi N, Rossetti L, Bottoli A, et al. Comparison of the effects of latanoprost, travoprost, and bimatoprost on circadian intraocular pressure in patients with glaucoma or ocular hypertension. Ophthalmology 2006;113:239-46.

22. Cardascia N, Vetrugno M, Trabucco T, et al. Effects of travoprost eye drops on intraocular pressure and pulsatile ocular blood flow: a 180-day, randomized, doublemasked comparison with latanoprost eye drops in patients with open-angle glaucoma. Curr Ther Res Clin Exp 2003;64:389-400.

23. Chiselita D, Antoni I, Medvichi R, et al. Comparative analysis of the efficacy and safety of latanoprost, travoprost and the fixed combination timolol-dorzolamide; a prospective, randomized, masked, cross-over design study. Oftalmologia 2005:49:39-45.

24. Gandolfi S, Simmons ST, Sturm R, et al. Three-month comparison of Bimatoprost and Latanoprost in patients with glaucoma and ocular hypertension. Adv Ther 2001;:18:110-21.

25. Dubiner $\mathbf{H}$, Cooke D, Dirks M, et al. Efficacy and safety of bimatoprost in patients with elevated intraocular pressure: a 30-day comparison with latanoprost. Surv Ophthalmol 2001;45(4 Suppl):353-60S.
26. Noecker RS, Dirks MS, Choplin NT, et al. A six-month randomized clinical trial comparing the intraocular pressure-lowering efficacy of bimatoprost and latanoprost in patients with ocular hypertension or glaucoma. Am J Ophthalmol 2003;135:55-63.

27. Walters TR, Dubiner HB, Carpenter SP, et al. 24-hour IOP control with once-daily bimatoprost, timolol gel-performing solution, or latanoprost: a 1-month, randomized, comparative clinical trial. Surv Ophthalmol 2004;49(1 Suppl):26-35S.

28. Konstas AGP, Katsimbris JM, Lallos N, et al. Latanoprost $0.005 \%$ versus bimatoprost $0.03 \%$ in primary open-angle glaucoma patients. Ophthalmology 2005;112:262-6.

29. Dirks MS, Noecker RJ, Earl M, et al. A 3-month clinical trial comparing the IOPlowering efficacy of bimatoprost and latanoprost in patients with normal tension glaucoma. Adv Ther 2006;23:385-94.

30. Konstas AGP, Holló G, Irkec M, et al. Diurnal IOP control with bimatoprost versus latanoprost in exfoliative glaucoma: a crossover, observer-masked, three-centre study. Br J Ophthalmol 2007;91:757-60.

31. Netland PA, Landry T, Sullivan EK, et al. Travoprost compared with latanoprost and timolol in patients with open-angle glaucoma or ocular hypertension. Am J Ophthalmo 2001;132:472-84

32. Parrish RK, Palenberg P, Shau WP, et al. A comparison of latanoprost, bimatoprost, and travoprost in patients with elevated intraocular pressure: A 12-week, randomized, masked-evaluator multicenter study. Am J Ophthalmol 2003:135:688-703

33. Parmaksiz S, Yüksel N, Karabas VL, et al. A comparison of travoprost, latanoprost and the fixed combination of dorzolamide and timolol in patients with pseudoexfoliation glaucoma. Eur J Ophthalmol 2006;16:73-80.

34. Chen MJ, Chen YC, Chou CK, et al. Comparison of the effects of latanoprost and travoprost on intraocular pressure in chronic angle-closure glaucoma. J Ocul Pharmacol Ther 2006;22:449-54.

35. Garcia-Feijoo J, Martinez de la Casa JM, Castilloa A, et al. Circadian IOP-lowering efficacy of travoprost $0.004 \%$ ophthalmic solution compared to latanoprost $0.005 \%$. Curr Med Res Opin 2006;22:1689-97.

36. Konstas AGP, Kozobolis VP, Katsimpsis IE, et al. Efficacy and safety of latanoprost versus travoprost in exfoliative glaucoma patients. Ophthalmology 2007;114:653-7.

37. Denis PH, Lafuma A, Khoshnood B, et al. A meta-analysis of topical prostaglandin analogues intraocular pressure lowering in glaucoma therapy. Curr Med Res Opin 2007:23:601-8

38. Stewart WC, Kolkler AE, Stewart JA, et al. Conjunctival hyperemia in healthy subjects after short-term dosing with latanoprost, bimatoprost, and travoprost. Am J Ophthalmol 2003:135:314-20.

39. Stjernschantz JW. From PGF (2 alpha)-isopropylester to latanoprost: a review of the development of xalatan: The Proctor lecture. Invest Ophthalmol Vis Sci 2001:42:1134-45.

40. Arcieri ES, Santana A, Rocha FN, et al. Blood-aqueous barrier changes after the use of prostaglandin analogues in patients with pseudophakia and aphakia. Arch Ophthalmol 2005;123:186-92. 